\title{
Penerapan Teori Graf Pada Jaringan Komputer Dengan Algoritma Kruskal
}

\author{
Fajar Mahardika*) \\ Jurusan Pascasarjana Ilmu Komputer, Fakultas Komputer, Universitas Budi Luhur , Jakarta \\ Jl. Ciledug Raya No.10, RT.10/RW.2, Petukangan Utara, Pesanggrahan, Jakarta 12260, Indonesia \\ email: putrafajardika@gmail.com
}

Copyright $@ 2019$, Politeknik Harapan Bersama, Tegal

\begin{abstract}
Graph theory a branch of mathematics that studies graphs of a problem that arises. Problems related to graph theory include electricity grid planning, water networks, computer networks and so on. In this graph theory, many of the methods studied include Minimum Spanning Tree (MST). This MST method is used to determine a minimum of a graph. In this MST there is an algorithm which is a kruskal algorithm. This kruskal algorithm is used to determine the shortest distance or minimum tree of a graph. The author conducted several trials related to the algorithm to be used. The author also conducts literature studies to determine the existing problems. In this study, choosing graph theory on a computer network with the algorithm used is the kruskal algorithm. In this study the authors conducted several stages such as hypotheses, trials and results. The results of this study are graph theory can be applied to computer networks, the number of devices needed can be known and in this experiment the algorithm gives a very maximum total used.
\end{abstract}

Abstrak - Teori graf sebuah cabang ilmu matematika yang mempelajari tentang grafik dari sebuah permasalahan yang muncul. Permasalahan yang berkaitan dengan teori graf diantaranya dalam perencanaan jaringan listrik, jaringan perairan, jaringan komputer dan lain sebagainya. Dalam teori graf ini banyak metode yang dipelajari diantaranya yaitu Minimum Spanning Tree (MST). Metode MST ini digunakan untuk menentukan sebuah minimum dari sebuah graf. Dalam $M S T$ ini terdapat sebuah algoritma yang diantaranya yaitu algoritma kruskal. Algoritma kruskal ini digunakan untuk menentukan jarak terpendek atau pohon minimum dari sebuah graf. Penulis melakukan beberapa ujicoba berkaitan dengan algoritma yang akan digunakan. Penulis juga melakukan studi pustaka untuk menentukan permasalahan yang ada. Pada penelitian ini memilih teori graf pada sebuah jaringan komputer dengan algoritma yang digunakan yaitu algoritma kruskal. Dalam penelitian ini penulis melakukan beberapa tahapan seperti hipotesis, ujicoba dan hasil. Hasil dari penelitian ini adalah teori graf bisa diterapkan pada jaringan computer, jumlah perangkat yang dibutuhkan bisa diketahui dan dalam percobaan ini algoritma sangat memberikan total yang digunakan sangat menimum.

Kata Kunci - Teori Graf, Minimum Spanning Tree, Algoritma Kruskal.

*) Corresponding author: (Fajar Mahardika)

Email: putrafajardika@gmail.com

\section{PENDAHULUAN}

Peranan ilmu matematika tidak bisa dilepas dalam kemajuan teknologi dan ilmu pada saat ini. Hampir semua permasalahan yang ada pada kehidupan baik itu teknologi atau ilmu pengetahuan yang terjadi peranan ilmu matematika sangat memberikan solusi yang bisa digunakan baik itu dalam konseptual maupun yang lain. Dalam banyak hal yang ada didalam kehidupan ini yang meliputi unsur kajian umum, ilmu murni maupun ilmu terapan yang ada pada bidang teknologi dan ilmu pengetahuan sangat memerlukan peranan ilmu matematika. Dalam ilmu matematika terdapat sebuah teori graf yang merupakan sebuah cabang ilmu matematika yang sudah ada sejak dahulu. Teori graf ini awalnya muncul pada tahun 1736, yang diperkenalkan pertama kalinya oleh Euler pada sebuah jurnal teori graf yang berasal dari Swiss.

Dalam jangka waktu yang cukup lama teori graf ini berkembang pesat dengan awal kemajuannnya memperkenalkan mengenai optimasi yang bisa diselesaikan dengan pohon rentang minimum yang lebih dikenal dengan sebuatan Minimum Spanning Tree (MST) [1]. Algoritma Kruskal adalah salah satu algoritma yang digunakan untuk mendapatkan minimum spanning tree (MST) dengan bobot terkecil. Pada Algoritma Kruskal, sisi-sisi didalam graf diurutkan terlebih dahulu berdasarkan bobotnya dari kecil ke besar. Jaringan komputer sebuah hal uatama yang dibutuhkan dalam sebuah koneksi pada komputer yang saling terhubung. Kadang jaringan komputer hanya dilakukan dengan manual, hal ini yang menyebabkan banyak permasalahan yang sering terjadi setelah jaringan komputer selesai.

Tujuan dari penelitian ini adalah menerapkan dan mengimplementasikan teori Graf pada sebuah jaringan computer dengan menggunakan algoritma kruskal sehingga didapatkan sebuah jaringan yang optimal.

\section{PENELITIAN YANG TERKAIT}

Gagarin dkk tahun 2010 mengahsilkan penelitian perutean hierarki yang seimbang yang mencakup pencarian pohon yang disajikan dalam Algoritma 2 memberikan peningkatan yang signifikan berkenaan dengan konsumsi energi maksimum oleh node dan secara tidak signifikan meningkatkan bobot total pohon rentang routing di WSN's. Hal ini disebabkan struktur minimum spanning tree (MST) yang dihasilkan. Persamaan dengan penelitian penulis menggunakan Algoritma Minimum Spanning Tree (MST). Perbedaan dengan penelitian penulis sebelumnya pencarian hirarkis 
terdistribusi untuk perutean konsumsi energi seimbang mencakup pepohonan di jaringan sensor nirkabel (wireless sensor network/WSN's) sedangkan penulis Graf pada topologi jaringan komputer dengan algoritma kruskal [2].

Tao, dkk tahun 2011 melakukan penelitin mengenai simulasi dan seleksi untuk jalur optimal membangun jaringan komunikasi berdasarkan pengetahuan teori graf. Persamaan dengan penelitian penulis menggunakan algoritma kruskal. Perbedaan dengan penulis sebelumnya menggunakan matlab sedangkan penulis menggunakan Netbeans [3].

Implementasi Algoritma Kruskal Dalam Pengoptimalan Perencanaan Panjang Kabel Listrik (Studi Kasus PT.PLN Rayon Gombong). Dilakukan oleh Barokah tahun 2017. Dengan hasil 1. Hasil pohon rentang minimum dari perencanaan jaringan baru distribusi listrik PLN Rayon gombong yang diperoleh dengan algoritma kruskal adalah pohon rentang minimum dengan panjang $6.750 \mathrm{~m}$. Persamaan dengan penelitian penulis yaitu menggunakan algoritma kruskal. Perbedangan dengan penelitian penulis sebelumnya Pada Jaringan PLN dan Menggunakan Visual Studio sedangkan penelitian penulis Pada jaringan Komputer dan Menggunakan Netbeans [4].

Li, dkk (2016). Metode konfigurasi jaringan distribusi yang ditingkatkan berdasarkan algoritma minimum spanning tree (MST) dan aturan heuristik. Hasil penelitian melalui kombinasi algoritma MST dan peraturan heuristik yang disempurnakan, makalah ini menyajikan metode konfigurasi jaringan distribusi barul dengan tujuan meminimalkan kehilangan daya aktif. Algoritma yang diusulkan memiliki karakteristik sebagai berikut; (1) Solusi optimasi awal diperoleh dengan algoritma MST. Solusinya tidak bergantung pada topologi jaringan awal; (2) Solusi pengoptimalan awal mendekati solusi optimal, ini memberikan kondisi awal yang baik untuk prosedur pengoptimalan selanjutnya; (3) Berdasarkan peraturan heuristik yang diperbaiki, jumlah switch kandidat lebih jauh berkurang. Pengujian sistem membuktikan validitas dan kelayakan algoritma yang diusulkan. Metode yang diusulkan bisa mendapatkan hasil yang lebih baik dan memiliki efisiensi yang lebih tinggi dibandingkan dengan yang dilaporkan dalam makalah referensi lainnya [5].

Abrori (2014), pengujian optimalisasi jaringan kabel fiber optic di Universitas Islam Indonesia dari hasil penelitan menggunakan Algoritma Kruskal, Prim, Boruvka, dan Algoritma Solin pada garf kampus UII menghasilkan pohon perentang minimum yang sama yaitu; 1. Panjang total jalur jaringan kabel FO adalah 1.590 meter; 2. Panjang total kabel FO yang dibutuhkan adalah 4.700 meter. Hasil penelitian tersebut lebih minimum 23,2\% dibandingkan kenyataan yang terjadi pada jaringan kabel FO kampus UII saat ini, yaitu; 1. Panjang total jalur jaringan kabel FO adalah 2.050 meter; 2. Panjang total kabel FO yang dibutuhkan adalah 6.120 meter [6][12]. Loppies \& Manggau (2014) dengan bahasan tentang algoritma kruskal untuk mencari rute terpendek dalam sebuah jaringan komputer. Dengan hasil penelitian perbandingan antara algoritma kruskal, OSPF dan EIGRP dengan menggunakan tiga topologi jaringan komputer diantaranya mesh, star dan bus dengan hasil mencari rute-rute terpendek dari tiga topologi tersebut [7].

\section{TEORI GRAFT}

Teori Graf merupakan bagian dari ilmu matematika dan komputer mengani suatu graft struktur matematika, yang dinyatakan dalam $\mathrm{G}$ dimana $\mathrm{G}$ adalah terdiri dari atas himpunan $\mathrm{V}$ yang berisikan titik (vertex atau node). Pada Gbr 1 merupakan contoh dari sebuah graft yang mempunyai node salaing berhubungan [8].

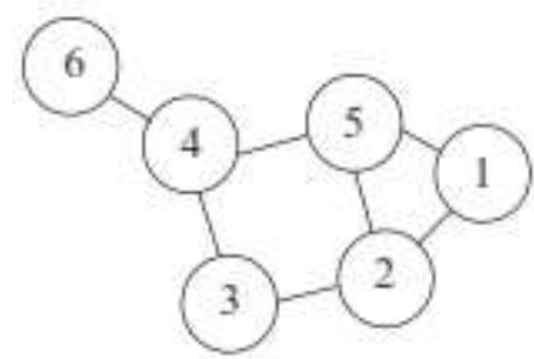

Gbr. 1 Gambaran mengenai graf.

Sebuah Graf dapat direpresentsikan menjadi berbagai macam struktur. Sebuah mempunyai sisi yang berarah atau disebut juga graf berrah atau directed graph. Suatu Graft berarah dengan mempunyai isi terbotbt disebut juga jaringan [9]. Disamping ilmu computer, teori graft sering juga digunakan dalam ilmu studi molekuler pada bidang kimia dan fisika, contohnya atom tiga dimensi. Ilmu lain dalam bidang sosiologi dan komunikasi teori graf digunakan seperti dalam menganalisis jaringan sosial atau lebih dikenal dengan nama jaringan komunikasi [8].

Dalam ilmi kmputer sebuh jaringan komputer dapat dikatakan merupakan sebuah himpnan interkoneksi antara 2 komputer autonomous atay lebih yang terhubung stu sama lain dengan menggunakan medi transmisi kabell serta tanpa kabel. Apabila sebuah computer dalam jaringan tersebut melakukan aktifita skontrol maka computer-komputer lainnya tidak melakukan control terhadap computer lain dengan akses penuh [10]. Sebuah jaringan komputer yang terhubung dalam satu himpunan mempunyai topologi yang brebeda-beda seperti sistem bus, token, ring, dan star. Topologi yang dipilih akan berpengaruh kepada kecepatan komunikasi dalam jaringan tersebut karena mempunyai karakteristik serta kelebihdan dan kekurangan dari topologi yang digunakan [11].

Salah satu algoritma yang digunakan untuk mendapatkan spanning tree (MST) dengan bobt terkecil adalah dengan menggunakan algoritma kruskal. Pada algoritma ini konsepnya adalah pada sisi-sisi didalam graf diurutkan terlebih dahulu berdasarkan bobot terkecil ke yang terbesar [12].

\section{METODE PENELITIAN}

Dalam penelitian ini pengumpulan data dilakukan dengan melakukan Observasi (Pengamatan) [13], pedokumentasian dan studi pustaka sebagai upaya menguatkan referensi pustaka penelitian [14]. Dalam penelitian ini penulis melakukan pencarian data menggunakan google form, seperti pada Gbr.2.

Apakah anda mengetahui teori graf bisa di implementasikan pada jaringan komputer?

sit mexpenters
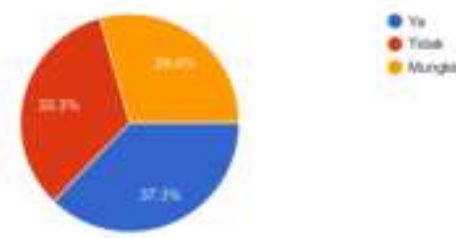

Gbr. 2 Data dari google from (sumber google form) 
Tahapan dalam penelitian seperti diperlihatkan pada Gbr.3 dan Gbr.4.

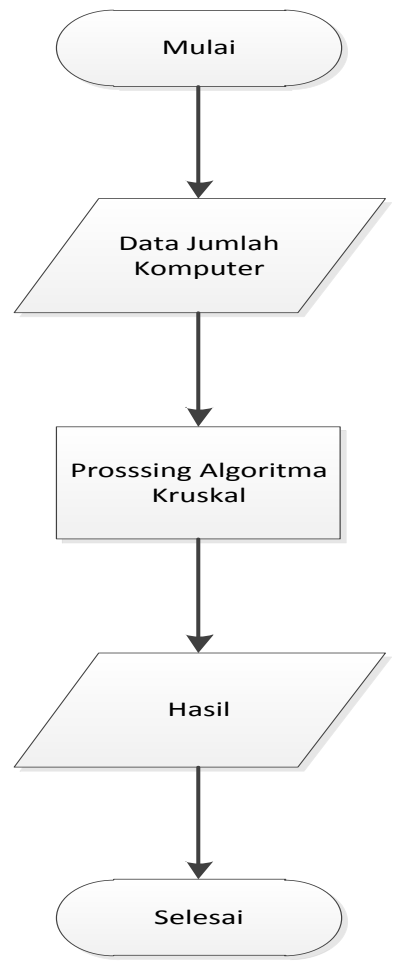

Gbr. 3 Flowchat Alur Tahapan Penelitian

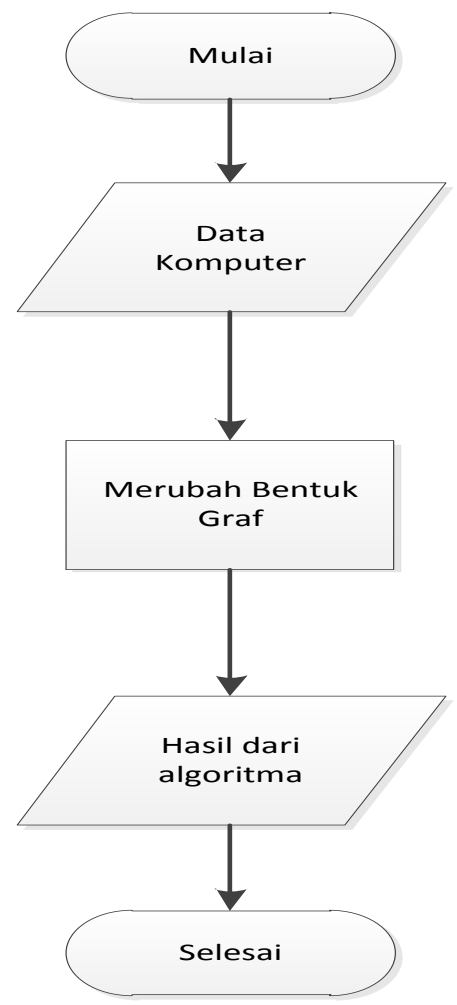

Gbr. 4 Alur Perubahan Graf

\section{HASIL DAN PEMBAHASAN}

A. Hasil observasi lapangan

Berdasarkan hasil Observasi yang sudah dilakukan terhadap objek penelitian didapatkan hasil gambaran jaringan fisik seperti pada Gbr.5.
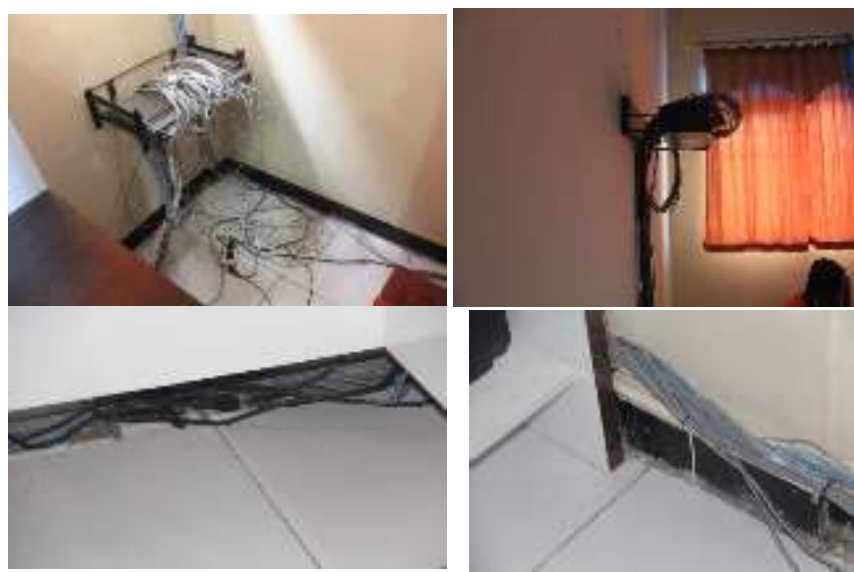

Gbr. 5 Gambaran Visual Hasil Observasi dalam tahapan dokumentasi

\section{B. Hasil Uji Coba}

Hasil dari uji coba dengan bantuan aplikasi yang telah dibuat sebelumnya dengan menggunakan aplikasi berbasis Netbeans menghasilkan hasil, diantaranya:

1) Tahapan uji coba dengan data 3 komputer, 1 hub dan 0 router. Dalam tahapan uji coba ini dengan hasil sebagai berikut pada Gbr.6.

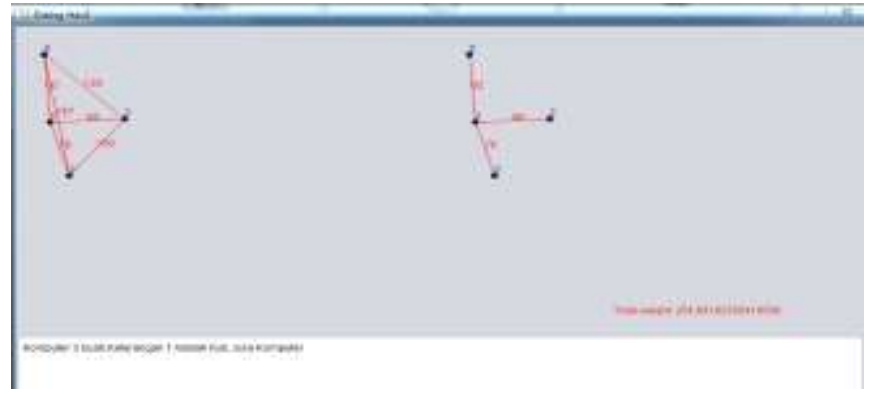

Gbr. 6 Uji coba data 3 komputer, 1 hub dan 0 router

- Hasil yang tidak menggunakan algoritma

Dalam hasil pada Gbr.7 ini menunjukan 6 garis yang menghubungkan 4 titikl (simpul) perhitungan pada Tabel 1 sebagai berikut: 


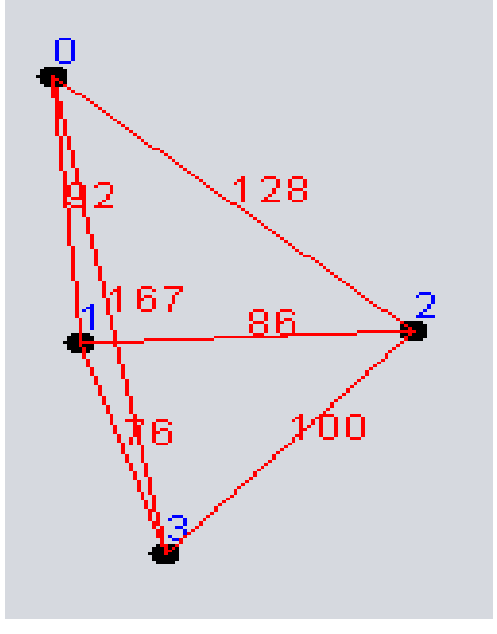

Gbr.7 Hasil tidak menggunakan algoritma

TABEL I

6 GARIS DAN 4 SIMPUL

\begin{tabular}{|c|c|c|c|}
\hline No & Simpul 1 & Simpul 2 & Bobot \\
\hline 1 & 0 & 1 & 92 \\
\hline 2 & 0 & 3 & 167 \\
\hline 3 & 0 & 2 & 128 \\
\hline 4 & 1 & 2 & 86 \\
\hline 5 & 1 & 3 & 76 \\
\hline 6 & 2 & 3 & 100 \\
\hline
\end{tabular}

Dalam tabel 1 di atas menjadi total adalah $92+167+128+86+76+100=649 \mathrm{~cm}$ dibagi 100 menjadi 6,49 meter.

\section{- Hasil yang menggunakan algoritma}

Dalam hasil ini menunjukan 3 garis yang menghubungkan 4 titik (simpul) seperti Gbr.8 dan hasil perhitungan diperlihatkan pada Tabel II.

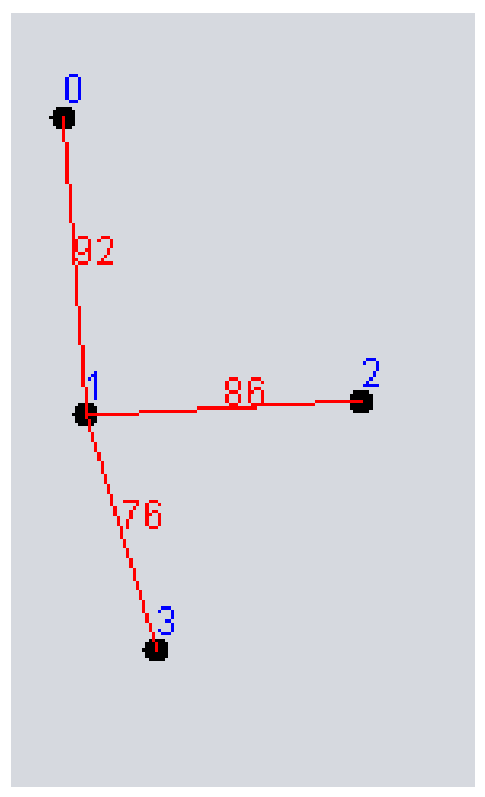

Gbr. 8 Hasil menggunakan algoritma
TABEL II

3 GARIS DAN 4 SIMPUL

\begin{tabular}{|c|c|c|c|}
\hline No & Simpul 1 & Simpul 2 & Bobot \\
\hline 1 & 0 & 1 & 92 \\
\hline 2 & 1 & 2 & 86 \\
\hline 3 & 1 & 3 & 76 \\
\hline
\end{tabular}

Pada Tabel II di atas menjadi total adalah $92+86+76=254$ cm dibagi 100 menjadi 2,54 meter.

\section{2) Tahapan Pengujian}

Tahapan uji coba dengan data 11 komputer, 4 hub dan 1 router. Dalam tahapan uji coba ini dengan hasil sebagai berikut:

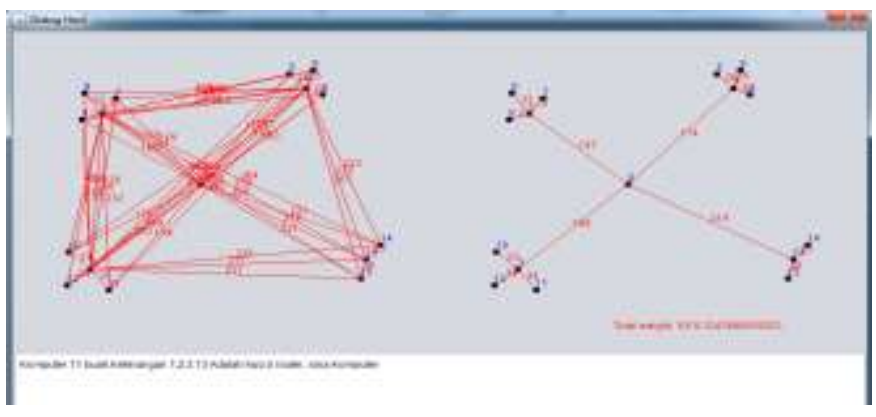

Gbr. 9 Uji coba data 11 komputer, 4 hub dan 1 router

\section{Evaluasi Sistem Jaringan}

Dari hasil analisis tersebut dibagi menjadi 2 bagian yaitu tanpa algoritma dan menggunakan algoritma kruskal.

a) Data yang tidak menggunakan algoritma kruskal

Pada Gbr.10 diketahui terdapat 15 simpul dengan masingmasing simpul yang terhubung terdapat garis yang memiliki bobot setiap garis yang terhubung. Berdasarkan graf tersebut akan di cari total panjang kabel. Berikut pada Tabel III yang menjelaskan tentang simpul dan bobotnya.

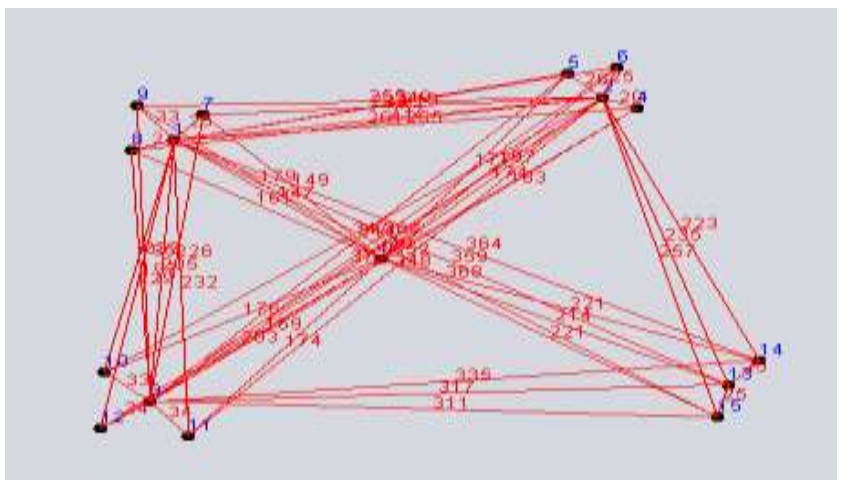

Gbr. 10 Hasil Analisis 11 Komputer tidak menggunakan algoritma kruskal 
TABEL III

SIMPUL DAN BOBOT DARI GRAF TIDAK MENGGUNAKAN ALGORITMA KRUSKAL

\begin{tabular}{|c|c|c|c|}
\hline No & Simpul 1 & Simpul 2 & Bobot \\
\hline 1 & 0 & 1 & 147 \\
\hline 2 & 0 & 7 & 149 \\
\hline 3 & 0 & 9 & 179 \\
\hline 4 & 0 & 8 & 161 \\
\hline 5 & 0 & 3 & 169 \\
\hline 6 & 0 & 10 & 176 \\
\hline 7 & 0 & 11 & 174 \\
\hline 8 & 0 & 12 & 203 \\
\hline 9 & 0 & 13 & 214 \\
\hline 10 & 0 & 15 & 221 \\
\hline 11 & 0 & 14 & 221 \\
\hline 12 & 0 & 2 & 174 \\
\hline 13 & 0 & 5 & 171 \\
\hline 14 & 0 & 6 & 197 \\
\hline 15 & 0 & 4 & 183 \\
\hline 16 & 3 & 14 & 335 \\
\hline 17 & 3 & 13 & 317 \\
\hline 18 & 3 & 15 & 311 \\
\hline 19 & 2 & 13 & 255 \\
\hline 20 & 2 & 14 & 223 \\
\hline 21 & 2 & 15 & 257 \\
\hline 22 & 3 & 1 & 205 \\
\hline 23 & 3 & 7 & 226 \\
\hline 24 & 3 & 9 & 183 \\
\hline 25 & 3 & 8 & 255 \\
\hline 26 & 1 & 10 & 229 \\
\hline 27 & 1 & 3 & 192 \\
\hline 28 & 1 & 11 & 232 \\
\hline 29 & 1 & 12 & 255 \\
\hline 30 & 1 & 14 & 364 \\
\hline 31 & 1 & 13 & 359 \\
\hline 32 & 1 & 15 & 368 \\
\hline 33 & 1 & 2 & 255 \\
\hline 34 & 1 & 5 & 249 \\
\hline 35 & 1 & 6 & 219 \\
\hline 36 & 1 & 4 & 264 \\
\hline 37 & 2 & 1 & 212 \\
\hline 38 & 2 & 7 & 255 \\
\hline 39 & 2 & 8 & 264 \\
\hline 40 & 2 & 9 & 249 \\
\hline 41 & 3 & 2 & 328 \\
\hline 42 & 3 & 6 & 348 \\
\hline 43 & 3 & 4 & 340 \\
\hline 44 & 3 & 5 & 332 \\
\hline 45 & 2 & 3 & 376 \\
\hline 46 & 2 & 10 & 357 \\
\hline 47 & 2 & 12 & 390 \\
\hline 48 & 2 & 11 & 348 \\
\hline
\end{tabular}

Jadi total bobot yang dihitung tanpa menggunakan algoritma kruskal adalah sebesar 12091 centimeter dibagi dengan $100=120,91$ meter. b) Data yang menggunakan algoritma kruskal

Pada Gbr. 11 mendapatkan hasil yang menggunakan algoritma kruskal dengan 15 simpul dan garis berbobot. Berikut pada Tabel IV dari hasil analisis yang menggunakan algoritma.

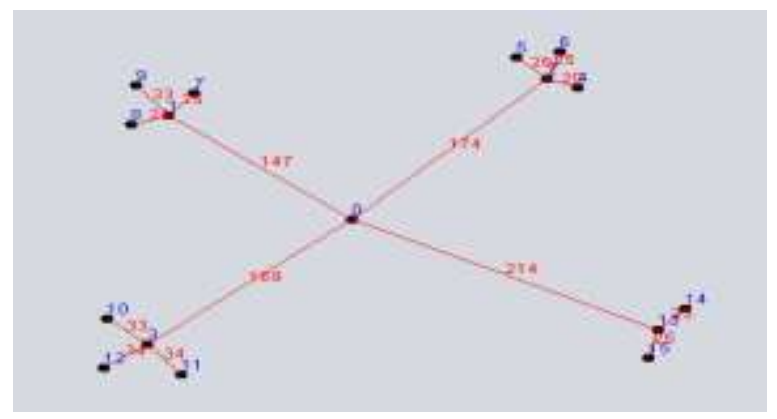

Gbr. 11 Hasil Analisis 11 Komputer Menggunakan Algoritma

TABEL IV

SIMPUL DAN BOBOT DARI GRAF MENGGUNAKAN ALGORITMA KRUSKAL

\begin{tabular}{|l|l|l|l|}
\hline No & Simpul 1 & Simpul 2 & Garis berbobot \\
\hline 1 & 0 & 1 & 147 \\
\hline 2 & 0 & 2 & 174 \\
\hline 3 & 0 & 3 & 169 \\
\hline 4 & 0 & 13 & 214 \\
\hline 5 & 1 & 9 & 33 \\
\hline 6 & 1 & 7 & 25 \\
\hline 7 & 1 & 8 & 21 \\
\hline 8 & 3 & 10 & 33 \\
\hline 9 & 3 & 12 & 34 \\
\hline 10 & 3 & 11 & 34 \\
\hline 11 & 13 & 14 & 25 \\
\hline 12 & 13 & 15 & 25 \\
\hline 13 & 2 & 4 & 20 \\
\hline 14 & 2 & 6 & 25 \\
\hline 15 & 2 & 5 & 26 \\
\hline
\end{tabular}

Jadi total bobot yang dihitung dengan algoritma kruskal adalah: $147+174+169+214+33+25+21+33+34+34+25+25+20$ $+25+26=1005$ centimeter dibagi $100=10,05$ meter.

Pembuktian dari uji coba dengan data 11 komputer, 4 hub dan 1 router seiperlihatkan pada Gbr.12.

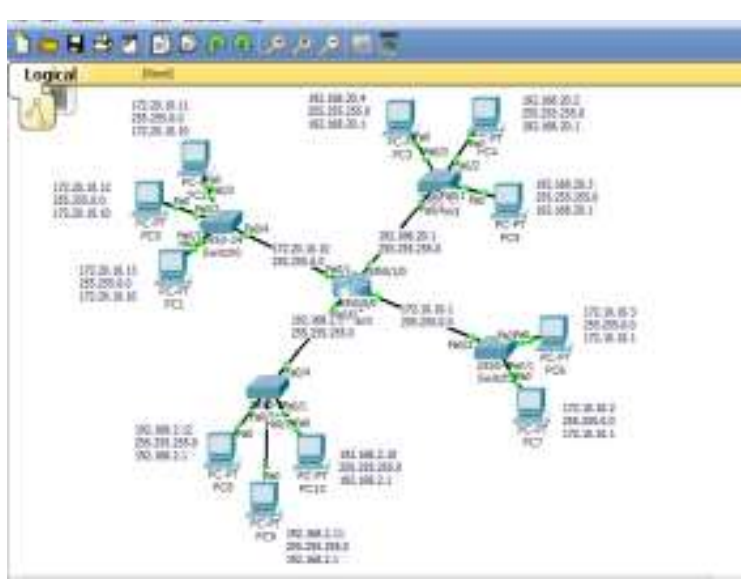

Gbr. 12 Pengujian dengan cisco 


\section{KESIMPULAN}

Berdasarkan hasil penelitian dan pengujian maka kesimpulan diambil adalah hasil tanpa menggunakan algoritma kruskal dengan hasil $12.091 \mathrm{~cm}$ dibagi dengan $100=120,91$ meter. Hasil tersebut bisa di lihat pada Gambar 4.40 dan juga Tabel 4.18. Hasil yang menggunakan algoritma kruskal dengan hasil $1.005 \mathrm{~cm}$ dibagi 100 $=10,05$ meter. Pada 2 data yang dihasilkan merupakan bukan penerapan dari algoritma kruskal pada jaringan laboratorium komputer, dikarenakan setiap komputer saling berdekatan tetapi menyambung kepada hub yang lebih jauh. Prinsip dari algoritma kruskal sendiri yaitu mencari jarak terdekat (pohon rentang minimum) sedangkan dari hasil malah sebaliknya dengan jarak yang jauh. Dengan kesimpulan tersebut 2 data bukan merupakan implementasi atau penerapan dari sebuah algoritma kruskal itu sendiri. Dari hasil tersebut bisa di lihat bahwa penerapan algoritma kruskal pada sebuah jaringan komputer masih kurang tepat jika komputer melebihi jumlah dari 11 komputer atau setiap hub sendiri lebih dari 3 komputer.

Dari penelitian yang dilakukan, peneliti menggunakan metode minimum spanning tree dan menggunakan algoritma kruskal masih bisa dikembangkan diantaranya adalah pada form analisis bisa ditambahkan ukuran ruangan, pada saat algoritma kruskal bisa menggunakan router dan juga hub, serta bisa menggunakan metode pengujian dan algoritma yang lain.

\section{UCAPAN TERIMA KASIH}

Penulis mengucapkan terima kasih kepada semua pihak yang telah membantu dalam pembuatan jurnal ini, para pembimbing, dan STMIK Amikom Purwokerto sebagai tempat belajar sewaktu Studi S1 serta Universitas Budi Luhur Jakarta sebagai tempat belajar S2.

\section{DAFTAR PUSTAKA}

[1] B. I. Ketut, Teori Graph dan Aplikasinya. Surabaya: Unesa University Press, 2007.
[2] A. Gagarin, S. Hussain, and L. T. Yang, "Distributed hierarchical search for balanced energy consumption routing spanning trees in wireless sensor networks," J. Parallel Distrib. Comput., vol. 70, no. 9, pp. 975982, Sep. 2010.

[3] S. Tao, L. Xiuzhi, W. Yanyan, C. Yanli, and C. Dayin, "A matlab simulation of the kruskal algorithm for erecting communication network," in 2011 International Conference on Electronics, Communications and Control (ICECC), 2011, pp. 41-43.

[4] B. F.F, "Implementasi Algoritma Kruskal Dalam Pengoptimalan Perencanaan Panjang Kabel Listrik (Studi Kasus PT.PLN Rayon Gombong)," STMIK Amikom Purwokerto, 2017.

[5] H. Li, W. Mao, A. Zhang, and C. Li, "An improved distribution network reconfiguration method based on minimum spanning tree algorithm and heuristic rules," Int. J. Electr. Power Energy Syst., vol. 82, pp. 466-473, Nov. 2016.

[6] M. Abrori and N. Ubaidillah, "Pengujian Optimalisasi Jaringan Kabel Fiber Optic Di Universitas Islam Indonesia Menggunakan Minimum Spanning Tree," J. Fourier, vol. 3, no. 1, p. 49, Apr. 2014.

[7] H. D. L. Stanly and X. M. Fransiskus, "Algoritma Kruskal Untuk Menentukan Rute Terpendek Pada Jaringan Komputer," J. Ilm. Mustek Anim Ha, vol. 3, no. 3, 2014.

[8] R. Vivit Wardah, "Kolaborasi dan graf komunikasi artikel ilmiah peneliti bidangmpertanian: studi kasus pada jurnal penelitian danmpengembangan pertanian serta indonesian Journal of Agricultural Science," J. Perpust. Pertan., vol. 17, no. 1, pp. 10-21, 2008.

[9] F. Mahardika and H. Marcos, "Penerapan Algoritma Graf Welch Powel Pada Penjadwalan Mata Kuliah Dan Jadwal Asisten Study Kasus Forum Asisten STMIK Amikom Purwokerto," Simetris J. Tek. Mesin, Elektro dan Ilmu Komput., vol. 8, no. 2, p. 825, Nov. 2017.

[10] S. Melwin, Pengantar jaringan komputer. Yogyakarta: Penerbit ANDI, 2005.

[11] S. Andi and G. Dhani, "Memilih Topologi Jaringan Dan Hardware Dalam Desain Sebuah Jaringan Komputer," Inform. Pertan., vol. 16, no. 2, pp. 1037-1053, 2007.

[12] T. L. Tambunan, "Pengoptimalan Jaringan Distribusi Air Dengan Menggunakan Algoritma Kruskal Pada Perusahaan Daerah Air Minum (PDAM) Tirtanadi Cabang Tuasan," UNIMED., 2012.

[13] S. M.P, Petunjuk Praktis Untuk Peneliti Pemula. Yogyakarta: Gadjah Mada University Press, 2004.

[14] Sugiyono, Metode penelitian pendidikan:(pendekatan kuantitatif, kualitatif dan $R \& D$ ). Bandung: Alfabeta, 2008. 